Egyptian

Orthodontic Journal

\title{
COLOR CHANGES ASSOCIATED WITH PROSEAL
}

\author{
Ismail HA ${ }^{1}$, El-Kalza RA ${ }^{2}$, Abdel-Raouf $\mathrm{AA}^{3}$ \\ ABSTRACT: \\ This in-vitro study was conducted to evaluate enamel \\ color changes associated with the use of a highly-filled, fluoride- \\ releasing enamel sealant (Proseal). A sample of 60 freshly \\ extracted premolar teeth were collected according to clear selection \\ criteria. The teeth were randomly divided into a control and three \\ experimental groups. \\ Brackets were 6onded to the teeth using Transbond XT \\ composite paste in only two of the experimental groups after \\ conditioning the whole buccal surface with 37\% phosphoric acid \\ for 15 seconds. In Group I, Transbond XT primer was applied to \\ the etched enamel surface while Proseal enamel sealant was \\ applied in Group II. In Group III, Proseal enamel sealant was \\ applied to the etched enamel surface with no bracket bonding. The \\ samples were then subjected to a staining and photo aging protocol \\ in an attempt to simulate the oral environment. In groups $I$ and \\ II, brackets were debonded and then the enamel surface was \\ finished and polished using a 12-fluted carbide burs on low speed \\ followed by rubber cup and polishing paste. Samples in Group III \\ and the control group received only enamel polishing. Enamel color \\ was spectrophotometrically evaluated at three intervals; at \\ baseline (T0), following debonding and finishing (T1), and after \\ resubjecting the samples to the same staining and photo aging \\ protocol (T3). CIE $\mathcal{L}^{*}, a^{*}, b^{*}$ order system was used for color \\ quantification and color differences $(\triangle E)$ were calculated.
}

1- Professor, Orthodontic Department. Alexandria University.

2- Lecturer, Orthodontic Department, Alexandria University.

3- Postgraduate student, Orthodontic Department, Alexandria University. 
Egyptian

Orthodontic Journal

Significant color change was found between baseline and (T1) measurements in all experimental groups. The highest mean of color change was reported in Group III. However the differences in color changes between Group I and Group II were non-significant, yet Group III exhibited a significant color change in regards to Groups I and II. All experimental groups showed clinically perceivable color change, as all values were exceeding the clinical color detection threshold of $\triangle \mathcal{D E}=3.7$ units. The same findings were reported for colorimetric differences calculated at the interval (T0-T2).

\section{INTRODUCTION}

A smile has been said to be one of the most important interactive communication skills of a person. Clearly a significant influence on facial attractiveness lies in possessing an attractive smile ${ }^{(1)}$. Smile attractiveness includes a number of important components, of which tooth color esthetics plays a crucial role ${ }^{(2)}$. Thus, tooth color is considered to be a major determinant in the visual assessment of a finished orthodontic case ${ }^{(3)}$.

Despite the many advances to improve the practice of orthodontics, enamel decalcifications, or white spot lesions, are the most frequent complication with fixed appliance therapy. ${ }^{(4)}$

White spot lesions are defined as subsurface enamel porosities from carious demineralization with a milky white opacity when located on smooth surfaces ${ }^{(5)}$. Changes in light scattering of the decalcified, porous enamel causes the white appearance. These white spot lesions rarely progress to significant cavitations and are generally not registered as caries requiring restorative treatment in the decayed, missing due to caries, filled teeth (DMFT) index. ${ }^{(6)}$

A review of literature in 2005 showed variations ranging from $2 \%$ to $97 \%$ for the prevalence of white spot lesions associated with orthodontic treatment ${ }^{(7)}$. Lack of compliance in maintaining adequate oral hygiene can predispose orthodontic patients to white spot lesions. ${ }^{(8)}$ 
Egyptian

Orthodontic Journal

Since the formation of white spot lesions is discouraging to a specialty whose goal is to improve esthetics in the dentofacial region, orthodontists should be proactive and take responsibility to prevent the development of such lesions by educating their patients about the importance of maintaining excellent dietary compliance and implementing a good oral hygiene regimen. This includes proper tooth brushing with a fluoridated dentifrice and a fluoride-containing mouth rinse ${ }^{(9)}$.

Unfortunately, these preventive measures depend on patient compliance. Poor patient compliance is a well-documented problem in the dental literature. This problem was highlighted by Geiger et al ${ }^{(10,11)}$ who found that only $12 \%$ to $13 \%$ of patients had excellent compliance in using a home fluoride rinse program as directed.

Various methods of decreasing demineralization have been examined that do not require patient compliance. Fluoride varnishes are an option that allows the orthodontist to control the timing and amount of fluoride used. However, varnishes usually require several in office applications ${ }^{(12)}$. Another method of decreasing demineralization without patient compliance is through fluoride-releasing bonding systems ${ }^{(13)}$. Caries inhibition has been demonstrated by both fluoride-releasing composites and glass-ionomer cements, but the bond strengths of these materials are lower than conventional composite resins and less than ideal for clinical treatment ${ }^{(14,15)}$. Resin-modified glass-ionomer cements possess desirable fluoride releasing properties and clinically acceptable bond strengths ${ }^{(16-18)}$. However, their clinical handling properties are less than ideal, deterring many practitioners. Accordingly, it could be conclusively stated that the ideal preventive measure should be independent of patient oral hygiene habits as well as easy to use by the clinician.

Sealant use is a promising method of decreasing enamel decalcification that fits the equation of being patient-independent as well as easy to use ${ }^{(19)}$. Placement of a resin sealant on the enamel surface prior to orthodontic bracket bonding has been suggested as a means of providing efficient sealing of the enamel surface against bacteria with subsequent protection against demineralization. ${ }^{(20,21)}$ 
The effectiveness of resin sealants to protect the enamel surface has been previously investigated ${ }^{(22-25)}$. Sealant material thickness, duration of protection, composition of the sealant material, distribution on the surface and endurance to oral stresses such as abrasion and thermal changes are imperative factors that affect the success of the sealant material.

As an attempt to overcome those shortcomings, Reliance Orthodontic Products released an enamel sealant specifically for orthodontic use. Proseal is a highly filled, light-cured, fluoride sealant. $\mathrm{Hu}$ and Featherstone $^{(26)}$ showed significant decreases in enamel demineralization on teeth treated with Proseal and subjected to simulated mechanical abrasion. The inclusion of filler particles imparts greater wear resistance than unfilled resins which is supposed to provide adequate resistance to mechanical stimuli from routine oral hygiene procedures. Accordingly, this would provide sustained, efficient and prolonged sealing of the enamel surface with subsequent protection against demineralization. The manufacturer also claims a final sealant polymerization of $100 \%$ without an oxygen inhibition layer; this should eliminate any loss of material due to non-polymerization at the surface ${ }^{(27)}$.

However, it is ought to be highlighted that sealant use might adversely affect tooth color. Sealants may change their chemical composition and appearance tending to discolor over time, usually becoming more yellow ${ }^{(28)}$. Moreover, even with complete removal of sealant on the surface during debonding by a finishing bur or polishing point, resin tags of 80 to $170 \mu \mathrm{m}$ can remain into enamel ${ }^{(29)}$. Hence, if the entire sealant is not removed after treatment, staining could continue after treatment, through accumulation of stains and aging. This would sequentially compromise tooth color which is considered an important determinant in the visual assessment of a finished orthodontic case, as well as sacrifice the overall patient satisfaction to treatment.

This in-vitro study was carried out to test the null hypothesis that the use of a fluoride-releasing, highly-filled, enamel sealant (Proseal) has no effect on enamel color. 
Egyptian

Orthodontic Journal

\section{MATERIALS AND METHODS}

\section{Study design:}

This study was an in vitro, experimental, comparative study designed to evaluate enamel color change associated with the use ofhighly-filled, fluoride-releasing enamel sealant (Proseal) ${ }^{*}$ with and without bracket bonding in comparison to a conventional orthodontic adhesive system (Transbond XT) ${ }^{*}$.

\section{Sample selection and preparation:}

In order to calculate an appropriate sample size, the threshold of clinically detectable color change of $\Delta \mathrm{E}=3.7^{(30)}$ was used as a mean difference for comparison between two groups using a t-test. The standard deviation of color change was set at $3.0^{(31)}$. At $\alpha=0.05$ and a power of 0.80 , the sample size estimator ${ }^{* * *}$ yielded 12 samples. It was decided to collect 15 samples for each group for a total sample size of 60 .

Immediately after extraction, the teeth were cleaned and thoroughly debrided under running water. Roots were scaled and cleaned of soft tissue debris using handscaler and then stored in an aqueous solution of thymol $(0.1 \%)$ at room temperature to prevent dehydration ${ }^{(32)}$. A black container was used for storage so that any possible effects of light are eliminated ${ }^{(33)}$.

At the onset of the study, each tooth was prepared by cutting its root below the cemento-enamel junction using a diamond disk under water cooling. Transparent auto polymerized acrylic resin ${ }^{\dagger \dagger}$ was mixed according to the manufacturer's instructions. Each tooth crown was then positioned in the center of a custom-made, cylindrical metal ring containing unset acrylic resin with the buccal surface uppermost and completely exposed to facilitate examination of the enamel surface, while the lingual surface and the apical area were completely covered with acrylic resin. The inner surface of the ring was lightly smeared with petroleum jelly ${ }^{\dagger \dagger t}$ to facilitate easy detachment of the acrylic moulds. The acrylic resin was allowed to set before removal of the metal rings.

\footnotetext{
* Proseal, Reliance Orthodontic Products, Itasca, Illinois.

** Transbond TM XT, Light cure orthodontic adhesives.REF 712-035.3M UNITEK. California, USA.

*** http://www.statstodo.com/SSiz2Means_Pgm.php\#Single calculation.

$\dagger$ Scaler H5/33 Hygienist / JaquetteErgoLight Steel Alloy.

$\dagger$ Meliodent,HerauseKulzer, Hanau, Germany.

tit Vaseline, Unilever South Africa Ltd.
} 
An impression of each specimen was made using a plastic round mould filled with heavy bodied polyvinyl siloxane i $^{\dagger \dagger}$. After setting, a small square-shaped window $(4 \mathrm{~mm} \times 4 \mathrm{~mm})$ was cleanly cut using a surgical scalpel and blade no. $11^{\dagger+1 \dagger \dagger}$ in the negative replica corresponding to the center of the buccal surface. This was of prime importance to standardize the area of enamel surface analyzed by the spectrophotometer. The mould replica was then painted by water proof black color.

\section{The Spectrophotometer}

A digital spectrophotometer ${ }^{*}$ was used in study. It measures the traditional shades (VITA Classic and Vita 3D Master), in addition to the CIE L*a*b* system (Figure 1).

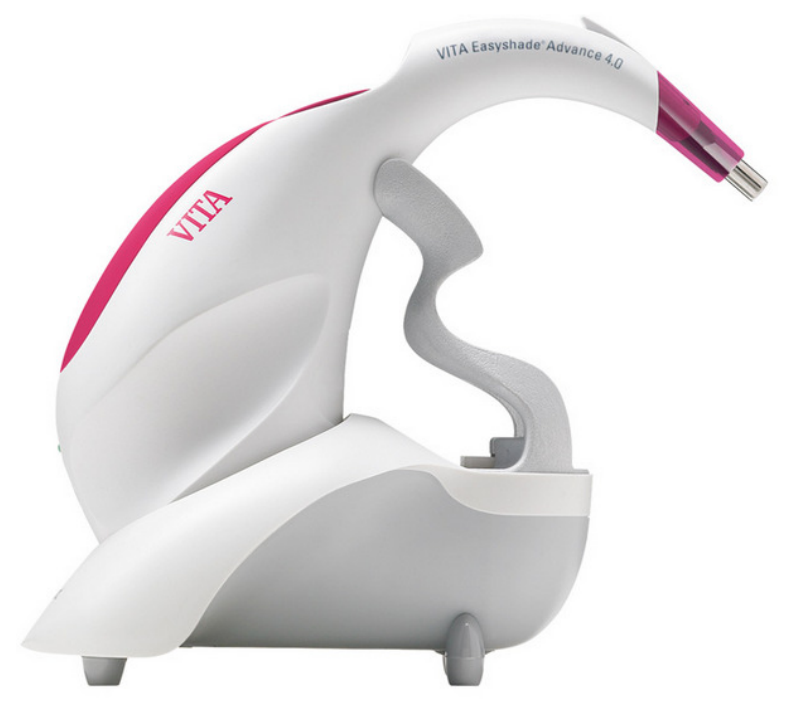

Fig. 1: VITA Easy shade spectrophotometer for tooth shade evaluation.

\footnotetext{
tit Speedex, Coltene/Whaledent AG, Switzerland.

titi' Swan-Morton Ltd, England.

\#ITA Easy shade Spectrophotometer Model\# DEAYSAS, stvseriennumen, CBU, H013015, Germany.
} 
Egyptian

Orthodontic Journal

\section{Color measurement:}

Color measurements were made according to the (Commission Internationale de l'Eclairage) CIE L*a*b* order systems where:

$\mathrm{L}^{*}$ corresponds to the value or degree of lightness.

$\mathrm{a}^{*}$ coordinates designate position on $\mathrm{red} /$ green axis.

$b^{*}$ coordinates designate position on yellow/blue axis.

The spectrophotometer was calibrated to a white ceramic tile supplied by the manufacturer before color measurements of each sample. A base line color assessment $\mathrm{T}_{0}$ was done for all teeth. Prior to color measurement, all teeth were cleaned with a rubber cup at low speed $(25,000 \mathrm{rpm})$ with a mixture of oil-free non-fluoridated pumice ${ }^{\S}$ and water for 30 seconds and then thoroughly rinsed with running water. The black rubber covering was placed to cover each sample exposing only a standardized widow for color measurement. The measurements were taken by a single operator according to the manufacturer's instructions. The steel probe of the spectrophotometer was placed perpendicular and flushed with the tooth surface to be analyzed. All enamel color recordings were made on wet enamel surfaces as advised by the manufacturer.

\section{Grouping:}

The samples were randomly assigned into 4 groups of 15 teeth each.

\section{Group I (Conventional Bonding-Transbond XT Group)}

The entire buccal surface of each tooth was etched using 37\% phosphoric acid ${ }^{\S \S}$ gelfor 15 seconds, rinsed under running water and then dried using oil-free and moisture-free compressed air for 10 seconds. The samples were then inspected for the characteristic dull-white frosted appearance of adequately etched enamel. A single coat of primer TransbondXT was applied in a thin uniform layer on the etched enamel surface, thinned with a gentle stream of oil-free and moisture-free

- Shinhung, Seoul, Korea.

$\S$ Dentsply, Milford, Del.

$\S \S$ Phosphoric Acid Etching Gel, 37\% conc. 3M EPSEAG, Germany.

Volume 44 - December 2013 
compressed air then light cured for 20 seconds. The black rubber cover was placed before bracket bonding to control bracket positioning. Standard edgewise premolar brackets were then bonded tithe teeth in the center of the prepared window in the rubber cover using light cure composite resin (Transbond XT) .This corresponds to the center of the buccal surface of the tooth. Excess composite was removed from around each bracket base with a sharp dental scaler and then light cured for 20 seconds (10 seconds from the mesial and 10 seconds from distal aspects of each bracket).

\section{Group II (Proseal group)}

The teeth were etched using the same etching technique employed for Group I.A single coat of Proseal (Figure 2) was applied according to the manufacturer's instruction in a thin layer on the entire buccal surface using a brush, thinned with a gentle stream of oil-free and moisture-free compressed air then light cured with a conventional halogen light curing unit $^{\S \S \S}$ for 20 seconds. Brackets were bonded following the same protocol for Group I.

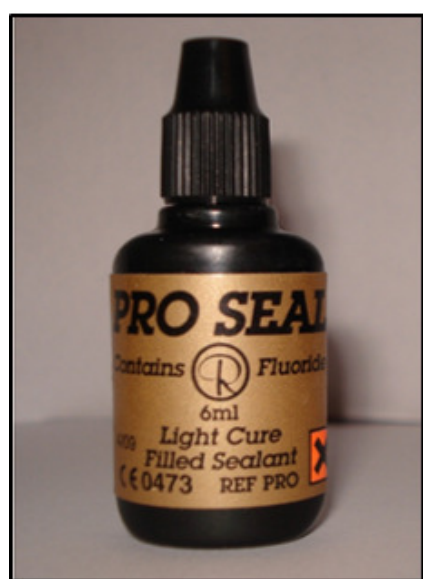

Fig. 2: Proseal supplied in a dark light-resistant container.

$\downarrow$ Leone S.p.A. Sesto Fiorentino - Firenze, Italy.

$\S \S \S$ EliparTM $^{\mathrm{TM}} 500$ Halogen Curing Light 3M ESPE, Germany.

Volume 44 - December 2013 
Egyptian

Orthodontic Journal

\section{Group III ('Proseal only' -without adhesive resin and brackets)}

The teeth were etched using the same etching protocol used in Groups I and II. A single coat of Proseal was applied according to the manufacturer's instructions in a thin uniform layer on the etched enamel surface using a brush, thinned with a gentle stream of oil-free and moisture-free compressed air then light cured for 20 seconds. No brackets were bonded in this group.

\section{Group IV (Control Group)}

The control group received only enamel prophylaxis. It was used to offset the effect of staining and photo aging on virgin enamel and maintained for comparative evaluation.

\section{Staining procedure:}

All specimens were stored in each of the following solutions consecutively; each for one week ${ }^{(34)}$.

- The specimens were first stored in $300 \mathrm{ml}$ of coffee solution at room temperature. Instant coffee" powder (3.6 g) was dissolved in $300 \mathrm{ml}$ of boiling water as per the manufacturer's recommendation. After 10 minutes of stirring, the solution was filtered through a filter paper.

- Tea" solution was prepared by immersing two prefabricated tea bags $(2 \times 2 \mathrm{~g})$ into $300 \mathrm{ml}$ of boiling distilled water for 10 minutes.

- $300 \mathrm{ml}$ of Cola "'(carbonated beverage) was used ready from the market.

After 1 week in each solution, the specimens were gently rinsed with distilled water for 5 minutes and blotted dry with tissue paper.

The coffee and tea solutions were freshly prepared daily and all solutions were changed daily to avoid changes in the concentrations of the solutions ${ }^{(32)}$.

- Nescafe Classic, Nestle.

-. Yellow label Tea. Lipton.

.. Pepsi Arabia.

Volume 44 - Decem6er 2013 
Egyptian

Orthodontic Journal

\section{Photoaging:}

All specimens were subjected to accelerated artificial photo aging with the use of a light-emitting apparatus '.".

This involves the exposure of the specimens to a 24-hour continuous irradiation of $50,000 \mathrm{~kJ} / \mathrm{m}^{2}$. This corresponds to aluminance of approximately 135,000 Luxat $400 \mathrm{~nm}$ at $38^{\circ} \mathrm{C}$ black body temperature. This procedure induces aging equivalent to that of exposure to sun irradiation of 30 days ${ }^{(35)}$ which was deemed adequate because the labial surfaces of crowns are not exposed to ambient light during ordinary conditions.

\section{Debonding:}

All brackets in (Groups I and II) were debonded using a bracket removing plier. The specimens were clamped to a bench top with a C-clamp while the brackets were debonded.

\section{Clean-up procedures}

\section{Groups I and II}

Residual adhesive resin was removed with a 12-fluted tungsten carbide bur ${ }^{\text {(36) }}$ using a light unidirectional brushstroke at low speed $(25,000 \mathrm{rpm})$ without water cooling. The extent of the overall resin removal was determined by visual inspection of the dry enamel surfaces through magnifying loupes under the dental operating light as well as by constant examination of the surface with a dental explorer. Polishing was done with rubber cup with pumice slurry with water for 30 seconds ${ }^{(37)}$ till a normal luster was restored to the enamel surface. The tooth surface was examined for any visible adhesive remnants using a magnifying loupe. Burs were only utilized once per surface.

Following the clean-up procedures, colorimetric measurements were performed on all groups $\left(T_{1}\right)$ employing the same steps and precautions previously mentioned.

---TUV 30W T8, Koninklijke Philips Electronics. AuraVF48, Alamria Pharmaceutical Company, Egypt.

^ Orthocare, Bradford, UK. 
Egyptian

Orthodontic Journal

\section{Groups III and IV:}

Groups III and IV (control group) received only enamel polishing (rubber cup and pumice for 30 seconds) before the colorimetric measurements.

\section{Post-finishing staining and photoaging}

Following clean-up, all specimens were subjected to a second cycle of staining and photo aging according to the previously described protocol.

Final color measurements $\left(\mathrm{T}_{2}\right)$ were performed on all groups. Color differences $(\Delta \mathrm{E})$ between the different intervals were calculated for each tooth using the following formula ${ }^{(38)}:\left(\Delta \mathrm{E}^{*}=\left[\left(\Delta \mathrm{L}^{*}\right)^{2}+\left(\Delta \mathrm{a}^{*}\right)^{2}+\left(\Delta \mathrm{b}^{*}\right)^{2}\right]^{1 / 2}\right.$.

\section{STATISTICAL ANALYSIS}

The statistical analysis was performed using Statistical Package for Social Sciences (SPSS version20).

Data obtained for the control and the study groups was expressed as means and standard deviations. For inter-group comparison, KruskalWallis test was used. Post hoc comparisons between groups were done using Mann-Whitney test. Significance value was set at $\mathrm{P} \leq 0.05$.

\section{RESULTS}

\section{1) Comparison of color change ( $\Delta E)$ among the study groups}

\section{i) Comparison of color change ( $\Delta \mathrm{E})$ from (T0) to (T1) among the study groups. (Table 1)}

There was a statistically significant difference in the color change from (T0) to (T1) between the control group and each of the experimental groups. The color difference was significantly higher for Group III ('Proseal only' $\Delta \mathrm{E}=9.76$ ) than the other two experimental groups (Group I $\Delta \mathrm{E}=4.93$ and Group II $\Delta \mathrm{E}=5.04)$. However, the color change between the two experimental groups (Groups I and II) was not statistically significant. 
Egyptian

Orthodontic Journal

Table (1): Comparison of color change $(\Delta \mathrm{E})$ from $\mathrm{T} 0$ to $\mathrm{T} 1$ among the study groups.

\begin{tabular}{|l|c|c|c|c|c|c|}
\hline \multicolumn{1}{|c|}{$\Delta$ E T0-T1 } & Group I & Group II & Group III & Group IV & F & $p$ \\
\hline Mean & 4.93 & 5.04 & 9.76 & 2.74 & & \\
\pm SD. & 2.19 & 2.61 & 5.50 & 1.03 & 9.55 & $0.007 *$ \\
\hline $\boldsymbol{P 1}$ & & 0.365 & $0.006^{*}$ & $0.023^{*}$ & & \\
\hline $\boldsymbol{P 2}$ & & & $0.022 *$ & $0.031^{*}$ & & \\
\hline $\boldsymbol{P 3}$ & & & & $0.001 *$ & & \\
\hline
\end{tabular}

ii) Comparison of color change ( $\Delta E)$ from $T 1$ to $T 2$ among the study groups. (Table 2)

There was a statistically significant difference in the color change from (T1) to (T2) between the control group and each of the experimental groups. The color difference was significantly higher for Group III ('Proseal only' $\Delta \mathrm{E}=6.67$ ) than the other two experimental groups (Group I $\Delta \mathrm{E}=5.04$ and Group II $\Delta \mathrm{E}=5.50$ ). However, the color change between the two experimental groups (Groups I and II) was not statistically significant.

Table (2): Comparison of color change $(\Delta \mathrm{E})$ from $\mathrm{T} 1$ to $\mathrm{T} 2$ among the study groups.

\begin{tabular}{|l|c|c|c|c|c|c|}
\hline $\boldsymbol{\Delta E}$ T1-T2 & Group I & Group II & Group III & Group IV & F & $\boldsymbol{p}$ \\
\hline Mean & 5.04 & 5.50 & 6.67 & 1.80 & 4.101 & $0.012^{*}$ \\
$\pm \mathrm{SD}$. & 2.50 & 1.79 & 3.72 & 0.97 & & \\
\hline $\boldsymbol{P 1}$ & & 0.064 & $0.042^{*}$ & $0.014^{*}$ & & \\
\hline $\boldsymbol{P 2}$ & & & $0.045^{*}$ & $0.006^{*}$ & & \\
\hline $\boldsymbol{P 3}$ & & & & $0.012^{*}$ & & \\
\hline
\end{tabular}

iii) Comparison of color change ( $\Delta \mathrm{E})$ from (T0) to (T2) among the study groups. (Table 3)

There was a statistically significant difference in the color change from (T0) to (T2) between the control group and each of the experimental groups. The color difference was significantly higher for Group III ('Proseal only' $\Delta \mathrm{E}=13.45$ ) than the other two experimental groups 
Egyptian

Orthodontic Journal

(Group I $\Delta \mathrm{E}=7.34$ and Group II $\Delta \mathrm{E}=8.07$ ). However, the color change between the two experimental groups (Groups I and II) was not statistically significant.

Table (3): Comparison of color change ( $\Delta \mathrm{E})$ from $\mathrm{T} 0$ to $\mathrm{T} 2$ among the study groups.

\begin{tabular}{|l|c|c|c|c|c|c|}
\hline$\Delta \mathbf{E}$ T0-T2 & Group I & Group II & Group III & Group IV & F & $\boldsymbol{p}$ \\
\hline Mean & 7.34 & 8.07 & 13.45 & 3.08 & 6.77 & $0.0101^{*}$ \\
\pm SD. & 2.88 & 2.92 & 5.76 & 0.64 & & \\
\hline $\boldsymbol{P 1}$ & & 0.368 & $0.021^{*}$ & $0.001^{*}$ & & \\
& & & & & & \\
\hline $\boldsymbol{P 2}$ & & & $0.021^{*}$ & $0.002^{*}$ & & \\
\hline $\boldsymbol{P 3}$ & & & & $0.001^{*}$ & & \\
\hline
\end{tabular}

\section{2) Color change in respect to the threshold of clinical detection}

Comparing the baseline measurement to the final measurement (T0-T2), all experimental groups showed a color change that exceeded the threshold of clinical detection. However, group III (Proseal only) exhibited a color change $(\Delta \mathrm{E}=13.45)$ that was more than three folds the threshold of clinical detection. Groups I and II showed a color difference that was almost twice the threshold of clinical detection $(\Delta \mathrm{E}=7.34$ and $\Delta \mathrm{E}=8.07)$ respectively. The control group $(\Delta \mathrm{E}=3.08)$ showed a color change that did not exceed the threshold of clinical detection.

\section{DISCUSSION}

In the present study, the effect of Proseal on the color of enamel was investigated when used as an orthodontic sealant and when used solely without orthodontic attachments.

In this study, all experimental groups showed color differences that exceeded the threshold of clinical detection between baseline $\mathrm{T} 0$ and $\mathrm{T} 1$ (group I $\Delta \mathrm{E}=4.93$, group II $\Delta \mathrm{E}=5.04$, and group III $\Delta \mathrm{E}=9.76$ ). Similar results were reported by Zaher et $\mathrm{al}^{(33)}$ where all experimental groups showed significant color change between baseline and finishing which exceeded the threshold for clinical color detection of $(\Delta \mathrm{E}=6.26$, 
$\Delta \mathrm{E}=6.68$, and $\Delta \mathrm{E}=5.67)$. This was attributed to the change in the refractive index of the enamel caused by the infiltration of the resin tags, which could modify the diffusely reflected light component, thus influencing the color parameters. Nonetheless, the difference in values of $\Delta \mathrm{E}$ between the two studies could account for the different methodologies applied, yet both exceeded the threshold of clinical detection. Diedrich ${ }^{(29)}$ reported that even after enamel finishing with a finishing bur or polishing point, resin tags can remain 80 to $170 \mu \mathrm{m}$ into the enamel and thus altering the refractive index of the region. Eliades et al ${ }^{(39,40)}$ further explained that tooth color alternation was a complex phenomenon that could involve several mechanisms, such as discoloration of the resin tag itself or staining by adsorption/ absorption of colorants from exogenous sources.

Although all experimental groups showed color differences that exceeded the threshold of clinical detection between baseline (T0) and (T1), Group III ('Proseal only') showed a significantly higher color difference than Groups I and II for the interval (T0-T1), while there was no statistically significant color change between Groups I and II. Group III exhibited a color change which was more than twice the threshold of clinical detection $(\Delta \mathrm{E}=9.76)$ while groups I and II exhibited lower $\Delta \mathrm{E}$ values. ( $\Delta \mathrm{E}=4.93$ and $\Delta \mathrm{E}=5.04$ respectively). This can be attributed to the thorough enamel finishing and polishing procedures that might outweigh the effect caused by the presence of the remaining resin tags ${ }^{(39)}$; whereas only enamel polishing was used in the 'Proseal only' group. Hence, it can be concluded that the adopted enamel cleaning technique could have a greater influence on post-debonding enamel discoloration than the type of sealant used. Similar conclusion was reached by Janabin et $\mathrm{al}^{(41)}$ and $\mathrm{Ye}$ et al ${ }^{(32)}$.

The former observations could suggest that enamel polishing using only rubber cup and pumice might not be sufficient to remove the stained resin tags and could in part account for the highest values of color change. This can give rise to a proposal to apply Proseal underneath the brackets as routinely practiced for conventional orthodontic adhesives; and not on the whole buccal surface as suggested by the manufacturer. This could facilitate resin tag removal during post-bonding clean-up procedures since finishing the whole buccal surface with a finishing bur was not proposed in the literature. 
Egyptian

Orthodontic Journal

Moreover, in this study all experimental groups showed an increase in $\Delta \mathrm{E}$ values between $\left(\mathrm{T}_{1}\right)$ and $\left(\mathrm{T}_{2}\right)$ that exceeded the threshold of clinical detection. Group III showed a difference in color change $(\Delta \mathrm{E}=6.67)$ that was 1.8 times the threshold of clinical detection, while groups I and II showed vales for color change that were 1.5 times the threshold of clinical detection. ( $\Delta \mathrm{E}=5.04$ and $\Delta \mathrm{E}=5.04$ respectively). This interval mimics the post-debonding behavior of resin remnants in the oral cavity. Trakyali et $\mathrm{al}^{(42)}$ reported no significant difference in color change following debonding, clean-up and photoaging. Hence, it was concluded that color changes of orthodontic bonding systems induced by photo aging can not be clinically observed. However, they criticized their findings that enamel discoloration induced by absorption of colorants from the oral environment was not investigated; which was executed in the current study. This explains the reported differences.

Furthermore, despite that there was no statistically significant difference in color change between Groups I and II for the measured intervals, Group II showed higher $\Delta \mathrm{E}$ values than Group I for all three studied intervals. This is despite the fact that both groups underwent the same clean-up procedures. This could suggest that the behavior of the highly-filled, fluoride releasing enamel sealant might be different from the conventional primer used in Group I in terms of color change. A larger sample size may help demonstrate a statistically significant difference.

Although the color change observed in the control group was below the critical threshold of clinical detection, yet the increase in values may be attributed to the storage in distilled water ${ }^{(33)}$ or to the uptake of stains by enamel components as suggested by Jahanbin et al ${ }^{(41)}$. Similar color change in control groups was observed by Zaher et $\mathrm{al}^{(33)}$ and Jahanbin et $\mathrm{al}^{(41)}$.

According to the findings of this study, Proseal can be used as an enamel sealant under orthodontic brackets. It displayed similar color change to a conventional adhesive besides the added benefit of reducing demineralization reported in other studies. However its sole use would have a remarkable effect on tooth color which might not be tolerated. 
Egyptian

Orthodontic Journal

\section{CONCLUSIONS}

Based on the findings of this study:

1- The highly-filled, fluoride-releasing enamel sealant (Proseal) demonstrated similar color change to the conventional adhesive (Transbond XT) when the enamel surface was thoroughly finished and polished.

2- Proseal used alone on the enamel surface exhibited a remarkable color change.

\section{REFERENCES}

1. Havens DC, McNamara Jr JA, Sigler LM, Baccetti T. The role of the posed smile in overall facial esthetics. Angle Orthod. 2010; 80:322-8.

2. Shulman JD, Maupome G, Clark DC, Levy SM. Perceptions of desirable tooth color among parents, dentists and children. J Am Dent Assoc. 2004; 135: 595-604.

3. Pratik K. Sharma, Pranay Sharma. Dental Smile Esthetics: The Assessment and Creation of the Ideal Smile. SeminOrthod. 2012; 18:193-201.

4. Proffit WR, White RP, Sarver DM. Contemporary treatment ofdentofacial deformity. St Louis: C. V. Mosby, 2003. p. 681.

5. Summitt JB, Robbins JW, Schwartz RS. Fundamentals of operative dentistry: acontemporaryapproach. 3rd ed. Hanover Park, IL: Quintessence; 2006. p. 2-4.

6. Ogaard B. White spot lesions during orthodontic treatment: Mechanisms and fluoride preventive aspects. SeminOrthod.2008; 14:183-93.

7. Boersma JG, van der Veen MH, Lagerweij MD, Bokhout B, PrahlAndersen B. Caries prevalence measured with QLF after treatment with fixed orthodontic appliances: influencing factors. Caries Res.2005; 39:41-7.

8. Chapman JA, Roberts, George WE, Eckert GJ, Kula KS, Gonza'lezCabezas C. Risk factors for incidence and severity of white spot lesions during fixed orthodontic therapy. Am J OrthodDentofacial Orthop 2010;138:188-94. 
9. Bishara SE, Ostby AW. White spot lesions: formation, prevention, and treatment. SeminOrthod. 2008; 14:174-82.

10. Geiger AM, Gorelick L, Gwinnett AJ, Benson BJ. Reducing white spot lesions in orthodontic populations with fluoride rinsing. AmJOrthodDentofacialOrthop. 1992; 101:403-7.

11. Geiger AM, Gorelick L, Gwinnett AJ, Griswold PG. The effect of a fluoride program on white spot formation during orthodontic treatment. Am J OrthodDentofacialOrthop. 1988; 93:29-37.

12. Vivaldi-Rodriques, Demito CF, Bowman SJ, Ramos AL. The effectiveness of a fluoride varnish in preventing the development of white spot lesions. World J Orthod 2006; 7:138-44.

13. Donly $\mathrm{KJ}$, Istre $\mathrm{S}$, Istre $\mathrm{T}$. In vitro enamel remineralization at orthodontic band margins cemented with glass ionomercement. Am J OrthodDentofacialOrthop 1995; 107:461-4.

14. Fox NA, McCabe JF, Gordon PH. Bond strengths of Orthodonticbonding materials: an in vitro study. Br J Orthod 1991; 18:125-30.

15. Voss A, Hickel R, Mölkner S. S. In vivo bonding of orthodonticbrackets with glass ionomer cements. Angle Orthod 1993; 63:149-53.

16. Lippitz SJ, Staley RN, Jakobsen JR. An in vitro study of 24-hourand 30-day shear bond strengths of three resin-glass ionomercementsused to bond orthodontic brackets. Am J OrthodDentofacialOrthop. 1998;113:620-4.

17. Williams JA, Billington RW, Pearson GJ. A long term study of fluoride release from metal-containing conventional and resinmodified glass-ionomer cements. J Oral Rehabil. 2001; 28:41-7.

18. Schmitt JL, Staley RN, Wefel JS, Kanellis M, Jakobsen JR, KeenanPJ. Effect of fluoride varnish on demineralization adjacent to brackets bonded with RMGI cement. Am J OrthodDentofacialOrthop. 2002; 122:125-34.

19. Farrow ML, Newman SM, Oesterle LJ, Shekkhart WC. Filled and unfilled restorative materials to reduce enamel decalcification during fixed-appliance orthodontic treatment. Am J OrthodDentofacialOrthop. 2007; 132:578.e1-6. 
Egyptian

Orthodontic Journal

20. Tanna N, Kao E, Gladwin M, Ngan P. Effects of sealant and selfetching primer on enamel decalcification. Part I: An in-vitro study. Am J OrthodDentofacialOrthop 2009; 135:199-205.

21. Ghiz MA, Ngan P, Kao E, Martin C, Gunel E. Effects of sealant and self-etching primer on enamel decalcification. Part II: An in-vivo study. Am J OrthodDentofacialOrthop 2009; 135:206-13.

22. Frazier MC, Southard TE, Doster PM. Prevention of enamel demineralization during orthodontic treatment: an in vitro study using pit and fissure sealants. Am J OrthodDentofacialOrthop. 1996; 110:459-65.

23. Craig RG, Powers JM. Restorative dental materials. 11th ed. St Louis: Mosby; 2002 .p. 207-227.

24. Joseph VP, Rossouw PE, Basson NJ. Do sealants seal? ASE Minvestigation. J ClinOrthod. 1992; 26:141-4.

25. Ceen RF, Gwinnett AJ. Microscopic evaluation of the thickness of sealants used in orthodontic bonding. Am J Orthod 1980; 78:623-9.

26. $\mathrm{Hu} \mathrm{W}$, Featherstone JD. Prevention of enamel demineralization: an in-vitro study using light-cured filled sealant. Am J OrthodDentofacialOrthop 2005; 128: 592-600.

27. Pro Seal ${ }^{\mathrm{TM}}$ product features insert. Itasca Il: Reliance Orthodontics Products; 2005.

28. Karamouzos A, Athanasiou AE, Papadopoulos MA, Kolokithas G. Tooth-color assessment after orthodontic treatment: a prospective clinical trial. Am J OrthodDentofacialOrthop 2010; 138:537.e1-8.

29. Diedrich P. Enamel alterations from bracket bonding and debonding: a study with the scanning electron microscope. AmJOrthod 1981; 79:500-22.

30. Johnston WM, Kao EC. Assessment of appearance match by visualobservation and clinical colorimetry. J Dent Res 1989; 68: 819-22.

31. Joo HJ, Lee YJ, Lee DY, Kim YJ, Lim YK. Influence of orthodontic adhesives and clean-up procedures on the stain susceptibility of enamel after debonding. Angle Orthod 2011; 81: 334-40. 
Egyptian

Orthodontic Journal

32. Ye C, Zhao Z, Zhao Q, Du X, Ye J, Wei X. Comparison of enamel discoloration associated with bonding with three different orthodontic adhesives and cleaning-up with four different procedures. Journal of Dent. 2013; 41: 35-40.

33. Zaher AR, Abdalla EM, Abdel Motie MA, Rehman NA, Kassem $\mathrm{H}$, Athanasiou AE. Enamel color changes after debonding using various bonding systems. J Orthod 2012; 39: 82-8.

34. Mundim FM, Garcia LFR, Pires-De-Souza FCP. Effect of staining solutions and repolishing on color stability of direct composites. J Appl Oral Sci 2010; 18: 249-54.

35. Atlas Suntest Bulletin. Atlas Material Testing Solutions. Corporate bulletin. Geluhausen, Germany: Atlas, 1998.

36. Hosein I, Sherriff M, Ireland AJ. Enamel loss during bonding, debonding, and cleanup with use of a self-etching primer. Am J OrthodDentofacialOrthop 2004; 126: 717-24.

37. Pus MD, Way DC. Enamel loss due to orthodontic bonding with filled and unfilled resins using various clean-up techniques. Am J Orthod 1980; 77: 269-83.

38. Commission Internationale de l'Eclairage (CIE). Recommendations on uniform color spaces, color difference equations, psychometric color terms. Publication CIE No. 12(E-1.3.1) Paris: CIE 1978: 9-12.

39. Eliades T, Kakaboura A, Eliades G, Bradley TG. Comparison of enamel color changes associated with orthodontic bonding using two different adhesives. Eur J Orthod 2001; 23: 85-90.

40. Eliades T, Gioka C, Heim M, Eliades G, Makou M. Color stability of orthodontic adhesive resins. Angle Orthod 2004; 74: 391-3.

41. Jahanbin A, Ameri H, Khaleghimoghaddam R. Effect of adhesive types on enamel discoloration around orthodontic brackets. AustOrthod J 2009; 25: 19-23.

42. Trakyali G, Ozdemir FI, Arun T. Enamel color changes at debonding and after finishing procedures using five different adhesives. Eur J Orthod 2009; 31: 397-401. 